\title{
On The Persistence Of Selectivity And Market Timing Skills In Hedge Funds
}

\author{
John Muteba Mwamba, University of Johannesburg, South Africa
}

\begin{abstract}
This paper investigates the persistence of hedge fund managers' skills during periods of boom and/or recession. We consider a data set of monthly investment strategy indices published by Hedge Fund Research group. The data set spans from January 1995 to June 2010. We divide this sample period into four overlapping sub-sample periods that contain different economic cycles. We define a skilled manager as a manager who can outperform the market consistently during two consecutive sub-sample periods. We first estimate outperformance, selectivity and market timing skills using both linear and quadratic Capital Asset Pricing Model-CAPM. Persistence in performance is carried out in three different fashions: contingence table, chi-square test and cross-sectional auto-regression technique. The results show that fund managers have the skills to outperform the market during periods of positive economic growth only. This market outperformance is due to both selectivity and market timing skills. These results contradict the Efficient Market Hypothesis-EMH due to limited arbitrage opportunity.
\end{abstract}

Keywords: Selectivity and Market Timing Skills; Contingence Table; Chi-Square Test; Market Efficiency

\section{INTRODUCTION}

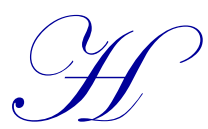

edge fund managers are continuously making investment decisions in uncertain market environments. Changes in market conditions affect their investment returns on a daily basis, hence making it difficult for many fund managers to deliver on the promise to provide their clients with an abnormal rate of returns. This paper investigates the performance of hedge funds based on efficient market hypothesis (EMH) assumptions.

We consider a sample of hedge fund returns collected from the Hedge Fund Research Inc. - HFRI. The database contains monthly returns of more than 6500 hedge fund managers from all over the world. The data set on these managers spans from January 1995 to June 2010. We subdivide this sample period into four sub-sample periods that include different market trends such as the 1998 Japanese crisis, the Dotcom bubble, the 2001 South African currency crisis, and the 2008-2009 sub-prime crisis. It is worth noting that the aim of this paper is not to identify crisis dates that are already known by average informed investors, but instead to assess the effectiveness of managers' skills during different market trends.

The subdivision of our entire sample into four sub-sample periods follows Capocci, Corhay and Hubner (2003), who use the Russell 3000 as the benchmark index to represent the market portfolio, and consider March 2000 as a separation date between sub-sample period 1 (before March 2000) and sub-sample period 2 (after March 2000). They argue that this benchmark index reached its maximum value of 858.48 points during a session in March 2000. During the sub-sample period 1, the Russell 3000 posted positive monthly returns in $70 \%$ of months (52 out of 74) with an average yearly return of $19.4 \%$, whereas during the sub-sample period 2 , the index posted positive monthly returns in $39 \%$ of months (12 out of 34 ), with an average yearly return of $-16.9 \%$.

Capocci, Corhay and Hubner (2003) argue that these "trends" are sufficiently strong to allow them to divide their entire sample period into two, i.e. bullish and bearish market "trends", without using complex methodologies to separate bullish, bearish and neutral months, since these methodologies would obviously not match the ones used by fund managers and other practitioners for their market timing decisions. 
As our sub-sample period 1 and sub-sample period 2 subdivision follows Capocci, Corhay and Hubner (2003), we extend their idea to include two more sub-sample periods in our study: sub-sample period 3, spanning from January 2003 to January 2007, and sub-sample period 4, spanning from February 2007 to June 2010. We consider sub-sample period 3 as a period of strong economic growth that precedes the sub-prime crisis. During the sub-sample period 3 the Russell 3000 index had positive monthly returns in 69\% of months (34 out of 49), with an average annual return of $15.01 \%$. In the same way we consider period 4 as a period of economic recession that includes the sub-prime mortgage crisis. During the sub-sample period 4 the Russell 3000 index had negative monthly return in $56 \%$ of months ( 23 out of 41 months) with an annualized rate of return of nearly $-11.7 \%$.

Therefore the four sub-sample periods that are used in this paper are as follows: sub-sample period 1, January 1995 to March 2000, which represents the economic recovery sample. Sub-sample period 2, April 2000 to Dec 2002, representing the low economic growth sample. Sub-sample period 3, January 2003 to January 2007, representing the strong economic growth sample. And sub-sample period 4, February 2007 to June 2010, representing the economic recession sample.

This subdivision makes this study different from previous studies on hedge fund performance analysis (Brown and Goetzman, 1995; Carhart 1997, Agarwal and Naik, 2000; and Ennis and Sebastian, 2003):

Firstly, because the performance analysis is carried out repeatedly during different economic cycles (bull and bear markets) instead of monthly (quarterly or semi-annually) periods as in abovementioned studies, we consequently refer to a skilled manager as a fund manager who performs consistently during both bull and bear markets. In other words, if a skilled manager wins (beats the market) in bull markets, he must show that he can also win in bear markets.

Secondly, contrary to the abovementioned authors who use the Jensen alpha in the CAPM model to measure managers' skills, this paper distinguishes three different types of managerial skills - namely, outperformance skill, selectivity skill and market timing skill. A manager with outperformance skill possesses the ability to generate an abnormal rate of returns as measured by a statistically significant Jensen alpha. A fund manager with selectivity skill is able to select financial assets that will perform better in the future, whereas a manager with market timing skill has the ability to predict correctly the future direction of the market, using advanced econometric methods. We use the Treynor-Mazuy (1966) "quadratic CAPM regression model" to obtain selectivity and market timing skill coefficients and the Jensen (1968) "linear CAPM regression model" to obtain the outperformance skill coefficient.

Although we cannot deny that some hedge fund managers do outperform the market and realize abnormal returns by luck, our results show that hedge fund managers possess outperformance skills during periods of positive economic growth. These results support the findings obtained in this regard by other researchers such as Franklin and Mustafa (2001), who also show that hedge funds that pay managers higher incentive fees have higher abnormal (excess) returns. They examine the persistence in excess returns of individual funds for a period of two years consecutively and find that the greater the persistence in excess returns, the more likely it is that hedge funds' performance is due to managers' skills rather than chance.

Hedge Fund Research Inc. shows that almost \$1.15 trillion of assets were under hedge fund management as of January 2010. The hedge fund industry continues to highlight the importance of including its investment products as a different asset class for diversification benefits; moreover, investors seek outperforming skilled managers who can render honest service and provide an abnormal rate of returns. Hence the issues of performance measurement of abnormal excess returns and skills in achieving these abnormal returns need careful attention.

These issues in some ways test whether the famous Fama (1965) efficient market hypothesis holds true in practice. Indeed, if markets are efficient, fund managers cannot take advantage of any differences in the securities market expectations regarding returns and risk to generate abnormal excess returns from active trading (see Blake, 1994). We argue that the market is itself made up of some irrational agents (see for example Kahneman and Tversky, 1982) that cause inefficiencies in the markets, and that investors do have heterogeneous expectations regarding securities' risk and returns. As a result, fund managers frequently adjust their portfolio weights to follow different investment strategies and identify any opportunities to beat the market. 
It should be noted that a fund manager can outperform the market by pure chance or by skill. A purely chance performance will not persist, while a skill-based performance will likely persist over periods of time. Therefore we define purely chance-based performance as the probability that the fund manager will outperform the market simply by factor luck, while we define a skill-based performance as the probability that the fund manager will be able to outperform the market based on his selectivity, and market timing skills.

A fund manager with selectivity skill uses his assumptions, expertise, and information about the market to take advantage of any mispricing ${ }^{1}$ that he believes is occurring in the market, whereas a manager with market timing skill uses his ability to forecast the prices movement of individual securities and/or an ability to forecast the general behaviour of security prices in the future and adjust his portfolio weight over time. Jensen (1968) argues that if fund managers really possess superior forecasting abilities, then they would be able to provide their investors with excess abnormal returns. In other words we refer to selectivity skill as the ability to select investments that will outperform the benchmark and market timing skill as the ability to forecast the future direction of security markets.

\section{METHODOLOGY}

\section{Performance Measurement Models}

Assume that excess return is generated by the following CAPM model:

$$
\mathrm{R}_{\mathrm{it}}-\mathrm{R}_{\mathrm{f}}=\alpha+\beta_{\mathrm{i} 1}\left(\mathrm{R}_{\mathrm{mkt}}-\mathrm{R}_{\mathrm{f}}\right)+\varepsilon_{\mathrm{it}}
$$

In equation (1), $R_{i t}$ represents the rate of returns on main strategy $i, \mathrm{R}_{\mathrm{mkt}}$ represents the rate of returns on the market portfolio, $R_{f}$ is the risk-free rate of returns, and $\beta_{i j}$ represents the sensitivity of expected returns of factor $i$ to market factors.

The intercept term in (1), $\alpha$, is referred to as alpha and measures the skills of the hedge fund manager. This model is based on the assumption that markets are efficient in the famous Fama (1965) efficient market hypothesis scenario, which relies on normality of asset return distribution and absence of transaction costs. In this scenario all market participants have the same beliefs about asset prices, which presumably suggest no mispricing in the market - that is, alpha and beta in (1) are statistically equal to zero and one respectively.

A skilled manager attempts to exploit any mispricing that occurs in the market, thereby generating a certain value of alpha statistically different from zero. Where the value of alpha is positive (negative) it is a signal that the investment strategy whose rate of returns is $R_{i t}$ is underpriced (overpriced) and the fund manager would gain from the strategy if s/he takes a long (short) position. A skilled manager will exhibit persistence in outperforming the market in different periods. Three different measures of managerial skills are used in this paper: the selectivity, the market timing, and the outperformance skills.

\section{The Selectivity and Market Timing Skills}

We use the Treynor and Mazuy (1966) performance measure as proxy for selectivity and market timing skills. For a fund manager with forecasting power, the returns on the managed portfolio will not be linearly related to the market return. This occurs because the manager will gain more than the market does when the market return is forecast to rise and he will lose less than the market does when the market is forecast to fall. Thus, his portfolio returns will be a concave function of the market returns. Using the following quadratic model:

$$
r_{i t}-r_{f}=\alpha_{i}+\beta_{1 i}\left(r_{m t}-r_{f}\right)+\beta_{2 i}\left(r_{m t}-r_{f}\right)^{2}+\varepsilon_{i t}
$$

\footnotetext{
${ }^{1}$ A mispricing of a security happens when, for an informed investor, its expected return (or risk estimate) is different from the market belief. If a security is underpriced (overpriced), then the market participants will expect its price to rise (fall) in the future.
} 
Treynor and Mazuy (1966) showed how the significance of $\beta_{2 i}$ provides evidence of the overperformance of a portfolio. Admati et al (1986) suggested that $\alpha_{i}$ in equation (2) can be interpreted as the selectivity component of performance and the $E\left[\beta_{2 i}\left(r_{m t}-r_{f}\right)^{2}\right]$ interpreted as the timing component of performance. The Treynor and Mazuy (1966) performance measure (TM) is therefore the sum of selectivity and market timing coefficients:

$$
T M=\alpha_{i}+\beta_{2 i} E\left[\left(r_{m t}-r_{f}\right)^{2}\right]
$$

\section{Two-Period Tests of Performance Persistence}

To investigate the persistence in performance of fund managers' skills we employ both parametric and nonparametric methods over two-period timeframes i.e. from sub-sample period 1 to sub-sample period 2; from subsample period 2 to sub-sample period 3; and from sub-sample period 3 to sub-sample period 4 . In fact our aim is to find out whether skilled managers are able to generate abnormal rates of return during consecutive different economic cycles.

We define a fund manager as a winner if the investment strategy that he uses generates a performance measure, i.e. selectivity or market timing coefficient that is higher than the median of all performance measures in that category, and a fund manager as a loser whose selectivity or market timing coefficient is lower than the median of all performance measures in that category.

For two-period tests of persistence in performance, we use a contingence table of winners and losers. Persistence in this context relates to fund managers who are winners in two consecutive periods (from sub-sample period 1 to sub-sample period 2 or from sub-sample period 2 to sub-sample period 3 or from sub-sample period 3 to sub-sample period 4) denoted by WW, or losers in two consecutive periods, denoted LL. Similarly, winners in the first period and losers in the second period are denoted by WL, while LW denotes the reverse. We employ three different techniques to detect the persistence in performance of each fund managers, namely the cross product ratio (CPR), the chi-square test statistic and the cross-sectional regression.

Firstly, the CPR is obtained from the contingence table of winners and losers as follows:

$$
C P R=\frac{(W W \times L L)}{(W L \times L W)}
$$

It captures the ratio of the funds which show persistence in performance to the ones which do not. Under the null hypothesis of no persistence in performance, the CPR is equal to one. This implies that each of the four categories denoted by WW, WL, LW, LL represent $25 \%$ of all funds.

To make a decision about the rejection of the null hypothesis, we make use of the Z-statistic given by:

$$
\mathrm{Z}-\text { statistic }=\frac{\operatorname{Ln}(\mathrm{CPR})}{\sigma_{\mathrm{Ln}(\mathrm{CPR})}}
$$

where $\sigma_{L n(C P R)}=\sqrt{\frac{1}{W W}+\frac{1}{W L}+\frac{1}{L W}+\frac{1}{L L}}$

For example, a Z-statistic greater than 1.96 indicates evidence of the presence of significant persistence in performance at a 5\% confidence level. (For more details see Kat and Menexe, 2003 and De Souza and Gokcan, 2004.) 
Secondly, the chi-square test statistic compares the distribution of observed frequencies for the four categories WW, WL, LW, and LL for each investment strategy with the expected frequency distribution. Previous studies carried out in performance analysis using the chi-square test statistic (Carpenter and Lynch, 1999 and Park and Staum, 1998) revealed that the chi-square test based on the numbers of winners and losers is well specified, powerful and more robust than other test methodologies, as it deals carefully with the presence of survivorship bias. The chi-square test statistic (see Agarwal and Naik, 2000) is given by:

$\chi_{C a l}^{2}=\frac{\left(W W-D_{1}\right)^{2}}{D_{1}}+\frac{\left(W L-D_{2}\right)^{2}}{D_{2}}+\frac{\left(L W-D_{3}\right)^{2}}{D_{3}}+\frac{\left(L L-D_{4}\right)^{2}}{D_{4}}$

where $\left\{\begin{array}{l}D_{1}=\frac{(W W+W L) \times(W W+L W)}{N} \\ D_{2}=\frac{(W W+W L) \times(W L+L L)}{N} \\ D_{3}=\frac{(L W+L L) \times(W W+L W)}{N} \\ D_{4}=\frac{(L W+L L) \times(W L+L L)}{N}\end{array}\right.$

We compare this statistic to the critical value of chi-square at $5 \%$ and $1 \%$ with degree of freedom equal to one.

Thirdly, the cross-sectional technique is an autoregressive regression of the form:

$\operatorname{Perf}_{\mathrm{t}}=\mathrm{a}+$ bPerf $_{\mathrm{t}-1}+\mathrm{u}_{\mathrm{t}}$

It models the relationship between the performance parameters of sub-sample period $t$ and that of subsample period $\mathrm{t}-1$. If the coefficient of performance parameters in previous sub-sample period is positive and statistically significant, it is an indication of persistence in performance in two consecutive sub-sample periods.

\section{EMPIRICAL RESULTS}

We collect monthly returns on 33 investment strategy indices from HFRI; each investment strategy represents a sole fund manager, whose label is shown in Appendix A. The data set on these managers spans from January 1995 to June 2010. To account for survivorship bias we consider only the sample periods of after 1994. According to Capocci and Hubner (2004), hedge fund data starting after 1994 is more reliable and do not contain any survivorship bias. The Russell 3000 index and the US three-month Treasury bill are used as proxies for market portfolio and risk free rate respectively.

Tables 6, 7 and 8 in Appendix B exhibit the estimates of the Jensen alpha, the selectivity and the market timing skill coefficients obtained from both linear and quadratic CAPM using 33 managers, each with 186 observations. $^{2}$

The winning/losing managers are identified by comparing the coefficient estimate of outperformance skill (selectivity or market timing) with the median outperformance skill (selectivity or market timing) of all managers that use the same category of investment strategies. We report in Tables 9, 10 and 11 in Appendix B these winners and losers for outperformance, selectivity and market timing skill respectively.

\footnotetext{
${ }^{2}$ We run 66 regressions using both linear and quadratic CAPM.
} 
Table 9 in Appendix B for instance illustrates that equity hedge in energy sector (EH_ENERG), fund of weighted composite in Euro (FWC_EUR), fund of weighted composite in British pound (FWC_GBP), macro systematic diversification (MCRO_SYST_DIV) and relative value in fixed income convertible arbitrage (RV_FIAB) managers show persistence patterns in outperformance skills because they are the consecutive winners in the first, second, third and fourth sub-sample periods. Given these tables of winners and losers we are now able to investigate the overall persistence in performance of the hedge fund industry in the two-period framework. Three techniques are used in this instance: the contingence table, the chi-square test statistic and the cross-sectional regression analysis.

Firstly, for the contingence table we use the cross product ratio and decide on the persistence of fund managers by comparing the Z-statistic value and the critical value of a normally distributed random variable with a mean of zero and unit variance. Table 1 exhibits the Z-statistic for the market outperformance, the selectivity and the market timing skills. The analysis of persistence in performance is carried out in a two-period framework - i.e. from sub-sample period 1 to sub-sample period 2 (P1-P2), from sub-sample period 2 to sub-sample period 3 (P2-P3), and from sub-sample period 3 to sub-sample 4 (P3-P4).

Table 1: Z-Statistic Value for Performance Persistence Skill

\begin{tabular}{|l|c|c|c|}
\hline & P1-P2 & P2-P3 & P3-P4 \\
\hline Outperform & 2.53056 & 1.83424 & 0.27797 \\
\hline Selectivity & 0.27797 & 0.27797 & 1.83424 \\
\hline Timing & 2.53056 & 0.16042 & 0.16042 \\
\hline
\end{tabular}

We summarize the analysis of persistence in performance in Table 2; for example at $5 \%$ significance level we find persistence in outperformance between sub-sample period 1 and sub-sample period 3 . This outperformance is mostly due to market timing skill during sub-sample period 1 and sub-sample period 2 . We find that at $7.5 \%$ or higher, this market outperformance is likely due to selectivity skill only during sub-sample period 2 and sub-sample period 3.

Table 2: Performance Persistence Analysis with Contingence Table

\begin{tabular}{|l|c|c|c|c|c|}
\hline \multicolumn{1}{|c|}{ A } & $\mathbf{1 \%}$ & $\mathbf{2 . 5 0 \%}$ & $\mathbf{5 \%}$ & $\mathbf{7 . 5 0 \%}$ & $\mathbf{1 0 \%}$ \\
\hline $\mathrm{Z}(1-\alpha / 2)$ & 2.575829 & 2.241403 & 1.959964 & 1.780464342 & 1.644953627 \\
\hline Outperform & no skill & skill 1-2 & skill 1-2 & skill 1-2 \& 2-3 & skill 1-2 \& 2-3 \\
\hline Selectivity & no skill & no skill & no skill & skill 2-3 & skill 2-3 \\
\hline Timing & no skill & skill 1-2 & skill 1-2 & skill 1-2 & skill $1-2$ \\
\hline
\end{tabular}

Secondly, for the chi-square test we compute the chi-square statistic for each manager's skill during the same periods; the results are summarized in Table 3 .

Table 3: Chi-Square Statistic Values

\begin{tabular}{|l|c|c|c|}
\hline & P1-P2 & P2-P3 & P3-P4 \\
\hline Outperform & 7.22843 & 3.553572 & 0.077355 \\
\hline Selectivity & 0.077355 & 0.077355 & 3.553572 \\
\hline Timing & 7.22843 & 0.025748 & 0.025748 \\
\hline
\end{tabular}

The performance persistence analysis using the chi-square test is summarized in Table 4 . According to this method there is evidence of market outperformance skill in hedge fund managers at the $1 \%, 2.5 \%$ and $5 \%$ significance level during sub-sample period 1 and sub-sample period 2 and at the $7.5 \%$, and $10 \%$ significance level between sub-sample period 1 through sub-sample period 3. However, this market outperformance is shown to be due to selectivity skill at $7.5 \%$ or higher (during sub-sample period 2 and sub-sample period 3), while market timing skill explains this overall outperformance at all levels of significance $(1 \%, 2.5 \%, 5 \%, 7.5 \%$ and $10 \%)$ during subsample period 1 and sub-sample period 2 only. One could argue that under the chi-square technique the overall market outperformance is likely due to market timing during sub-sample period 1 and sub-sample period 2. 
Table 4: Performance Persistence Analysis with Chi-Square Test

\begin{tabular}{|l|c|c|c|c|c|}
\hline \multicolumn{1}{|c|}{$\boldsymbol{\alpha}$} & $\mathbf{1 \%}$ & $\mathbf{2 . 5 0 \%}$ & $\mathbf{5 \%}$ & $\mathbf{7 . 5 0 \%}$ & $\mathbf{1 0 \%}$ \\
\hline CHI $\alpha$ & 6.634897 & 5.02388647 & 3.841459149 & 3.170053581 & 2.705543971 \\
\hline Outperform & skill 1-2 & skill 1-2 & skill 1-2 & skill 1-2 \& 2-3 & skill $1-2 \& 2-3$ \\
\hline Selectivity & no skill & no skill & no skill & skill 2-3 & skill $2-3$ \\
\hline Timing & skill 1-2 & skill 1-2 & skill 1-2 & skill 1-2 & skill 1-2 \\
\hline
\end{tabular}

Lastly, for the cross-sectional regression analysis we regress the performance parameters of the current period on those of previous period. Table 5 shows the coefficients of the previous performance (outperformance, selectivity and market timing) parameter and the p-value in brackets at the $5 \%$ significance.

Table 5: Performance Persistence Analysis with Cross-Sectional Regression

\begin{tabular}{|l|c|c|c|}
\hline & Table 5: Performance Persistence Analysis with Cross-Sectional Regression \\
\hline Outperform & P1-P2 & P2-P3 & P3-P4 \\
\hline Selectivity & $-0.1385(0.3481)$ & $\mathbf{0 . 5 7 3 1}(\mathbf{0 . 0 0 0 3})$ & $0.11240 .4108)$ \\
\hline Timing & $-0.2905(0.15)$ & $\mathbf{0 . 5 2 0 8}(\mathbf{0 . 0 0 0 0})$ & $0.0973(0.335)$ \\
\hline
\end{tabular}

In bold we highlight the manager's skill that persists over sub-sample period 2 to sub-sample period 3. The cross-sectional regression method shows that at 5\% significance level there is evidence of managers' outperformance which is due to selectivity skills during sub-sample period 2 and sub-sample period 3.

\section{CONCLUSION}

In this paper we have used three techniques (contingence table, chi-square and the cross-sectional regression) to assess the persistence in performance of hedge funds during the period between January 1995 and June 2010. Our results show that on average fund managers have skills to outperform the market during our entire sample period. However, this outperformance is likely due to market timing skill during recovery periods rather than selectivity skill. During recovery periods asset prices are expected to rise from the bottom, making it easy for investors to predict the direction of the market.

\section{AUTHOR INFORMATION}

John Muteba Mwamba, Senior lecturer, University of Johannesburg, Department of Economics and Econometrics. Office: D-ring 218, Auckland Park, 2006, South Africa. Tel: +27115594371; Fax: +27115593039. E-mail: johnmu@uj.ac.za

\section{REFERENCES}

1. Adamti, A., Bhattacharya, S., Pfleiderer, P. and Ross, S. A. (1986). On Timing and Selectivity. Journal of Finance 41(3), 715-730.

2. Agarwal, V., and Naik, N. Y. (2000). Multi-Period Performance Persistence Analysis of Hedge Funds. Journal of Financial and Quantitative Analysis, 35: 327-342.

3. Blake, D. (1994). Pensions Schemes and Pension Funds in the United Kingdom, Oxford University Press.

4. Brown, S.J., and Goetzman, W.N. (1995). Performance Persistence. Journal of Finance, 50: 679-698.

5. Capocci, D., and Hübner, G. (2004). An Analysis of Hedge Fund Performance. Journal of Empirical Finance, 11: 55-89.

6. Capocci, D. P. J. and Hübner, G. (2003). An Analysis of Hedge Fund Performance. Journal of Empirical Finance, 11: 55-89.

7. Carhart, M. (1997): On Persistence in Mutual Fund Performance. Journal of Finance, 52: 57-82.

8. Carpenter, J. N., and Lynch, W. A., (1999). Survivorship Bias and Attrition Effects in Measures of Performance Persistence. Journal of Financial Economics 54: 337-374.

9. De Souza and Gokcan (2004). Hedge Fund Investing: A Quantitative Approach to Hedge Fund Manager Selection and De-selection. Journal of Wealth Management, 6(4): 52-73.

10. Ennis, R. M., Sebastian, M. D., (2003). A Critical Look at the Case for Hedge Funds. Journal of Portfolio Management 29(4): 103-112. 
11. Fama, E. (1965). Portfolio Analysis in a Stable Paretian Market. Management Science, 11: 404-419.

12. Fama, E. F. (1984). The Information in Term Structure. Journal of Financial Economics, 13: 509- 528.

13. Franklin, R., and Mustafa, O., (2001): Hedge Fund Performance and Manager Skill. Journal of Futures Markets, 21(11): 1003-1028.

14. Jensen, M. (1968): The Performance of Mutual Funds in the Period 1945-196. Journal of Finance, 23: 389416.

15. Kahneman, D. and Tversky, A. (1982): Prospect Theory: An Analysis of Decision under Risk, Econometrica, 47: 263-291.

16. Kat, H. M. and Menexe, F. (2003): Persistence in Hedge Fund Performance: The True Value of a Track Record Working Paper; City University, London.

17. Park, J. M. and Staum, J. C. (1998): Performance Persistence in Alternative Investment, Working Paper, Paradigm Capital Management, Inc.

18. Treynor, J.L. and Mazuy, F. (1966): Can Mutual Funds Outguess the Market? Harvard Business Review, 44: 131- 136. 


\section{APPENDIX A}

The labels of investment strategies used throughout the paper:

1. ED: HFRI Event-Driven (Total) Index

- HFRI ED: Distressed/Restructuring Index: ED_RES

- HFRI ED: Merger Arbitrage Index: ED_MA

- HFRI ED: Private Issue/Regulation D Index: ED_PVT

2. $\quad$ EH: HFRI Equity Hedge (Total) Index:

- HFRI EH: Equity Market Neutral Index: EH_EMN

- HFRI EH: Quantitative Directional: EH_QUANT

- HFRI EH: Sector - Energy/Basic Materials Index: EH_ENERG

- HFRI EH: Sector - Technology/Healthcare Index: EH_TECH

- HFRI EH: Short Bias Index: EH_SBIAS

3. EM: HFRI Emerging Markets (Total) Index:

- HFRI Emerging Markets: Asia ex-Japan Index: EM_ASIA-JP

- HFRI Emerging Markets: Global Index: EM_GLOBAL

- HFRI Emerging Markets: Latin America Index: EM_LAT_AM

- HFRI Emerging Markets: Russia/Eastern Europe Index: EM_EAST-EU

4. FoF: HFRI Fund of Funds Composite Index:

- HFRI FOF: Conservative Index: FoF_CONSV

- HFRI FOF: Diversified Index: FoF_DIVERS

- HFRI FOF: Market Defensive Index: FoF_MKT-DFENS

- HFRI FOF: Strategic Index: FoF_STRATG

5. FWC: HFRI Fund Weighted Composite Index:

- HFRI Fund Weighted Composite Index CHF: FWC_CHF

- HFRI Fund Weighted Composite Index EUR: FWC_EUR

- HFRI Fund Weighted Composite Index GBP: FWC_GBP

- HFRI Fund Weighted Composite Index JPY: FWC_JPY

6. MCRO: HFRI Macro (Total) Index:

- HFRI Macro: Systematic Diversified Index: MCRO_SYST-DIV

7. $\quad$ RV: HFRI Relative Value (Total) Index:

- HFRI RV: Fixed Income-Asset Backed: RV_FIAB

- HFRI RV: Fixed Income-Convertible Arbitrage Index: RV_FICA

- HFRI RV: Fixed Income-Corporate Index: RV_FICORP

- HFRI RV: Multi-Strategy Index: RV_MSTRAT

- HFRI RV: Yield Alternatives Index: RV_YEILDA

Each of these investment strategies has 186 observations corresponding to 186 months that have been divided into four sub-sample periods. 


\section{APPENDIX B: ESTIMATIONS}

The Jensen alpha, the Treynor and Mazuy selectivity and market timing skills:

Table 6: The Jensen Alpha in Four Different Sub-Samples

\begin{tabular}{|c|c|c|c|c|}
\hline & Period 1 & Period 2 & Period 3 & Period 4 \\
\hline ED_RES & 1.2446 & 4.0072 & -2.5491 & 1.0325 \\
\hline ED_MA & 1.4114 & 3.9248 & -3.2206 & 1.0649 \\
\hline ED_PVT & 3.1563 & 3.318 & -2.9907 & 0.6832 \\
\hline EH_EMN & 1.3184 & 3.9088 & -3.3137 & 0.6879 \\
\hline EH_QUANT & 1.2188 & 3.9743 & -3.2506 & 0.9824 \\
\hline EH_ENERG & 2.2048 & 4.5177 & -2.4213 & 1.2246 \\
\hline EH_TECH & 2.2175 & 3.0635 & -3.552 & 1.4351 \\
\hline EH_SBIAS & 1.5101 & 4.333 & -3.2136 & 0.3137 \\
\hline EM_ASIA_JP & 0.107 & 3.3125 & -2.5831 & 1.2464 \\
\hline EM_GLOBAL & 0.1235 & 3.74 & -2.6995 & 1.6027 \\
\hline EM_LAT_AM & 0.5269 & 3.8463 & -2.7579 & 1.399 \\
\hline EM_EAST_EU & 0.359 & 5.7389 & -1.3109 & 1.0204 \\
\hline FoF_CONSV & 1.2804 & 3.7346 & -3.2047 & 0.6789 \\
\hline FoF_DIVERS & 0.975 & 3.5563 & -3.2089 & 0.7345 \\
\hline FoF_MKT_DFENS & 1.126 & 4.0049 & -3.3754 & 1.1051 \\
\hline FoF_STRATG & 1.0805 & 3.4978 & -3.1656 & 0.765 \\
\hline FWC_CHF & 1.001 & 3.754 & -3.2703 & 0.9516 \\
\hline FWC_EUR & 2.6996 & 3.8943 & -3.1264 & 1.0449 \\
\hline FWC_GBP & 1.3772 & 3.9738 & -2.9539 & 1.1042 \\
\hline FWC_JPY & 0.8706 & 3.5456 & -3.3317 & 0.9224 \\
\hline MCRO_SYST_DIV & 1.5006 & 3.9146 & -3.261 & 1.2557 \\
\hline RV_FIAB & 1.2953 & 4.4256 & -2.9145 & 1.3783 \\
\hline RV_FICA & 1.4912 & 4.3071 & -3.2849 & 1.4563 \\
\hline RV_FICORP & 0.8975 & 3.7594 & -2.8516 & 1.041 \\
\hline RV_MSTRAT & 1.1161 & 4.1035 & -3.0439 & 1.0154 \\
\hline RV_YEILDAT & 0.7523 & 4.3167 & -3.027 & 0.7878 \\
\hline
\end{tabular}

Table 7: Treynor and Mazuy's Selectivity Skill

\begin{tabular}{|l|c|c|c|c|}
\hline & Period 1 & Period 2 & Period 3 & Period 4 \\
\hline ED_RES & 0.4318 & 1.437 & -0.3075 & 0.9126 \\
\hline ED_MA & 0.3765 & 1.0465 & -0.7274 & 0.9159 \\
\hline ED_PVT & 2.0815 & 0.3718 & -0.2542 & 0.832 \\
\hline EH_EMN & 0.2374 & 0.7858 & -0.9431 & 0.5302 \\
\hline EH_QUANT & 0.5609 & 1.0867 & -0.9148 & 0.8303 \\
\hline EH_ENERG & 1.1395 & 0.2216 & -0.5327 & 0.8535 \\
\hline EH_TECH & 2.0292 & 0.0574 & -1.0279 & 1.0965 \\
\hline EH_SBIAS & -0.035 & 1.6677 & -0.9681 & 0.55 \\
\hline EM_ASIA_JP & -0.51 & 0.8198 & -0.0829 & 1.1731 \\
\hline EM_GLOBAL & -0.335 & 1.1221 & -0.4752 & 1.2493 \\
\hline EM_LAT_AM & 0.1751 & 0.7747 & -0.5407 & 1.1316 \\
\hline EM_EAST_EU & 0.4565 & 3.5317 & 1.4465 & 0.9317 \\
\hline FoF_CONSV & 0.3265 & 0.8012 & -0.8104 & 0.6118 \\
\hline FoF_DIVERS & 0.1732 & 0.6406 & -0.8068 & 0.567 \\
\hline FoF_MKT_DFENS & 0.1851 & 0.6135 & -0.7277 & 1.0937 \\
\hline FoF_STRATG & 0.3208 & 0.594 & -0.7859 & 0.6326 \\
\hline FWC_CHF & 0.1973 & 0.776 & -0.915 & 0.7799 \\
\hline FWC_EUR & 1.8878 & 0.915 & -0.7717 & 0.8829 \\
\hline FWC_GBP & 0.5687 & 0.9909 & -0.6063 & 0.9661 \\
\hline FWC_JPY & 0.0564 & 0.5637 & -0.9769 & 0.7023 \\
\hline MCRO_SYST_DIV & 0.601 & 0.4523 & -0.7864 & 1.3925 \\
\hline RV_FIAB & 0.2489 & 1.6582 & -0.6232 & 1.2448 \\
\hline
\end{tabular}


Table 7 cont.

\begin{tabular}{|l|c|c|c|c|}
\hline RV_FICA & 0.4369 & 1.4678 & -0.8169 & 0.9685 \\
\hline RV_FICORP & -0.056 & 0.9726 & -0.5844 & 1.038 \\
\hline RV_MSTRAT & 0.1353 & 1.1253 & -0.7093 & 0.7756 \\
\hline RV_YEILDAT & -0.162 & 1.1657 & -0.4551 & 0.6121 \\
\hline
\end{tabular}

Table 8: Treynor and Mazuy's Market Timing

\begin{tabular}{|c|c|c|c|c|}
\hline & Period 1 & Period 2 & Period 3 & Period 4 \\
\hline ED_RES & 0.0429 & 0.0422 & -0.0549 & 0.0019 \\
\hline ED_MA & 0.056 & 0.0473 & -0.0611 & 0.0023 \\
\hline ED_PVT & 0.0567 & 0.0484 & -0.0671 & -0.0023 \\
\hline EH_EMN & 0.057 & 0.0513 & -0.0581 & 0.0025 \\
\hline EH_QUANT & 0.0347 & 0.0474 & -0.0572 & 0.0024 \\
\hline EH_ENERG & 0.0562 & 0.0705 & -0.0463 & 0.0058 \\
\hline EH_TECH & 0.0099 & 0.0494 & -0.0619 & 0.0053 \\
\hline EH_SBIAS & 0.0815 & 0.0438 & -0.055 & -0.0037 \\
\hline EM_ASIA_JP & 0.0433 & 0.0409 & -0.0613 & 0.0067 \\
\hline EM_GLOBAL & 0.0242 & 0.043 & -0.0545 & 0.0023 \\
\hline EM_LAT_AM & 0.0185 & 0.0504 & -0.0543 & 0.0065 \\
\hline EM_EAST_EU & -0.005 & 0.0362 & -0.0676 & 0.0014 \\
\hline FoF_CONSV & 0.0503 & 0.0482 & -0.0587 & 0.0011 \\
\hline FoF_DIVERS & 0.0423 & 0.0479 & -0.0589 & 0.0026 \\
\hline FoF_MKT_DFENS & 0.0497 & 0.0557 & -0.0649 & 0.0002 \\
\hline FoF_STRATG & 0.04 & 0.0477 & -0.0583 & 0.0021 \\
\hline FWC_CHF & 0.0424 & 0.0489 & -0.0577 & 0.0027 \\
\hline FWC_EUR & 0.0391 & 0.0489 & -0.0577 & 0.0025 \\
\hline FWC_GBP & 0.0427 & 0.049 & -0.0575 & 0.0022 \\
\hline FWC_JPY & 0.043 & 0.049 & -0.0577 & 0.0034 \\
\hline MCRO_SYST_DIV & 0.047 & 0.0569 & -0.606 & -0.0021 \\
\hline RV_FIAB & 0.0552 & 0.0454 & -0.0561 & 0.0021 \\
\hline RV_FICA & 0.0556 & 0.046 & -0.0605 & 0.0076 \\
\hline RV_FICORP & 0.0503 & 0.0458 & -0.556 & 0.0001 \\
\hline RV_MSTRAT & 0.0518 & 0.0489 & -0.0572 & 0.0037 \\
\hline RV_YEILDAT & 0.0482 & 0.0517 & -0.063 & 0.0027 \\
\hline
\end{tabular}

The winners and losers series for different skills are show below.

Table 9: Winners/Losers in Outperformance Skill

\begin{tabular}{|c|c|c|c|c|}
\hline & Period 1 & Period 2 & Period 3 & Period 4 \\
\hline ED_RES & $\mathrm{L}$ & $\mathrm{W}$ & $\mathrm{W}$ & $\mathrm{W}$ \\
\hline ED_MA & $\mathrm{W}$ & $\mathrm{W}$ & $\mathrm{L}$ & $\mathrm{W}$ \\
\hline ED_PVT & $\mathrm{W}$ & $\mathrm{L}$ & $\mathrm{W}$ & $\mathrm{L}$ \\
\hline EH_EMN & $\mathrm{L}$ & $\mathrm{L}$ & $\mathrm{L}$ & $\mathrm{L}$ \\
\hline EH_QUANT & $\mathrm{L}$ & $\mathrm{W}$ & $\mathrm{W}$ & $\mathrm{W}$ \\
\hline EH_ENERG & $\mathrm{W}$ & $\mathrm{W}$ & $\mathrm{W}$ & $\mathrm{W}$ \\
\hline EH_TECH & $\mathrm{W}$ & $\mathrm{L}$ & $\mathrm{L}$ & $\mathrm{W}$ \\
\hline EH_SBIAS & $\mathrm{W}$ & $\mathrm{W}$ & $\mathrm{W}$ & $\mathrm{L}$ \\
\hline EM_ASIA_JP & $\mathrm{L}$ & $\mathrm{L}$ & $\mathrm{W}$ & $\mathrm{L}$ \\
\hline EM_GLOBAL & $\mathrm{L}$ & $\mathrm{L}$ & $\mathrm{L}$ & $\mathrm{W}$ \\
\hline EM_LAT_AM & $\mathrm{W}$ & $\mathrm{W}$ & $\mathrm{L}$ & $\mathrm{W}$ \\
\hline EM_EAST_EU & $\mathrm{W}$ & $\mathrm{W}$ & $\mathrm{W}$ & $\mathrm{L}$ \\
\hline FoF_CONSV & $\mathrm{W}$ & $\mathrm{W}$ & $\mathrm{W}$ & $\mathrm{L}$ \\
\hline FoF_DIVERS & $\mathrm{L}$ & $\mathrm{L}$ & $\mathrm{L}$ & $\mathrm{L}$ \\
\hline FoF_MKT_DFENS & $\mathrm{W}$ & $\mathrm{W}$ & $\mathrm{L}$ & $\mathrm{W}$ \\
\hline FoF_STRATG & $\mathrm{L}$ & $\mathrm{L}$ & $\mathrm{W}$ & $\mathrm{W}$ \\
\hline FWC_CHF & $\mathrm{L}$ & $\mathrm{L}$ & $\mathrm{L}$ & $\mathrm{L}$ \\
\hline FWC_EUR & $\mathrm{W}$ & $\mathrm{W}$ & $\mathrm{W}$ & $\mathrm{W}$ \\
\hline
\end{tabular}


Table 9 cont.

\begin{tabular}{|l|c|c|c|c|}
\hline FWC_GBP & W & W & W & W \\
\hline FWC_JPY & L & L & L & L \\
\hline MCRO_SYST_DIV & W & W & W & W \\
\hline RV_FIAB & W & W & W & W \\
\hline RV_FICA & W & W & L & W \\
\hline RV_FICORP & L & L & W & W \\
\hline RV_MSTRAT & W & L & L & L \\
\hline RV_YEILDAT & L & W & W & L \\
\hline
\end{tabular}

Table 10: Winners/Losers in Selectivity Skill

\begin{tabular}{|c|c|c|c|c|}
\hline & Period 1 & Period 2 & Period 3 & Period 4 \\
\hline ED_RES & $\mathrm{W}$ & $\mathrm{W}$ & $\mathrm{W}$ & $\mathrm{W}$ \\
\hline ED_MA & $\mathrm{L}$ & $\mathrm{W}$ & $\mathrm{L}$ & $\mathrm{W}$ \\
\hline ED_PVT & $\mathrm{W}$ & $\mathrm{L}$ & $\mathrm{W}$ & $\mathrm{L}$ \\
\hline EH_EMN & $\mathrm{L}$ & $\mathrm{W}$ & $\mathrm{W}$ & $\mathrm{L}$ \\
\hline EH_QUANT & $\mathrm{W}$ & $\mathrm{W}$ & $\mathrm{W}$ & $\mathrm{W}$ \\
\hline EH_ENERG & $\mathrm{W}$ & $\mathrm{L}$ & $\mathrm{W}$ & $\mathrm{W}$ \\
\hline EH_TECH & $\mathrm{W}$ & $\mathrm{L}$ & $\mathrm{L}$ & $\mathrm{W}$ \\
\hline EH_SBIAS & $\mathrm{L}$ & $\mathrm{W}$ & $\mathrm{L}$ & $\mathrm{L}$ \\
\hline EM_ASIA_JP & $\mathrm{L}$ & $\mathrm{L}$ & $\mathrm{W}$ & $\mathrm{W}$ \\
\hline EM_GLOBAL & $\mathrm{L}$ & $\mathrm{W}$ & $\mathrm{L}$ & $\mathrm{W}$ \\
\hline EM_LAT_AM & $\mathrm{W}$ & $\mathrm{L}$ & $\mathrm{L}$ & $\mathrm{L}$ \\
\hline EM_EAST_EU & $\mathrm{W}$ & $\mathrm{W}$ & $\mathrm{W}$ & $\mathrm{L}$ \\
\hline FoF_CONSV & $\mathrm{W}$ & $\mathrm{W}$ & $\mathrm{L}$ & $\mathrm{L}$ \\
\hline FoF_DIVERS & $\mathrm{L}$ & $\mathrm{W}$ & $\mathrm{L}$ & $\mathrm{L}$ \\
\hline FoF_MKT_DFENS & $\mathrm{L}$ & $\mathrm{L}$ & $\mathrm{W}$ & $\mathrm{W}$ \\
\hline FoF_STRATG & $\mathrm{W}$ & $\mathrm{L}$ & $\mathrm{W}$ & $\mathrm{W}$ \\
\hline FWC_CHF & $\mathrm{L}$ & $\mathrm{L}$ & $\mathrm{L}$ & $\mathrm{L}$ \\
\hline FWC_EUR & $\mathrm{W}$ & $\mathrm{W}$ & $\mathrm{W}$ & $\mathrm{W}$ \\
\hline FWC_GBP & $\mathrm{W}$ & $\mathrm{W}$ & $\mathrm{W}$ & $\mathrm{W}$ \\
\hline FWC_JPY & $\mathrm{L}$ & $\mathrm{L}$ & $\mathrm{L}$ & $\mathrm{L}$ \\
\hline MCRO_SYST_DIV & $\mathrm{W}$ & $\mathrm{W}$ & $\mathrm{W}$ & $\mathrm{W}$ \\
\hline RV_FIAB & $\mathrm{W}$ & $\mathrm{W}$ & $\mathrm{W}$ & $\mathrm{W}$ \\
\hline RV_FICA & $\mathrm{W}$ & $\mathrm{W}$ & $\mathrm{L}$ & $\mathrm{W}$ \\
\hline RV_FICORP & $\mathrm{L}$ & $\mathrm{L}$ & $\mathrm{W}$ & $\mathrm{W}$ \\
\hline RV_MSTRAT & $\mathrm{W}$ & $\mathrm{L}$ & $\mathrm{L}$ & $\mathrm{L}$ \\
\hline RV_YEILDAT & $\mathrm{L}$ & $\mathrm{W}$ & $\mathrm{W}$ & $\mathrm{L}$ \\
\hline
\end{tabular}

Table 11: Winners/Losers in Market Timing Skill

\begin{tabular}{|l|c|c|c|c|}
\hline & Period 1 & Period 2 & Period 3 & Period 4 \\
\hline ED_RES & L & L & W & W \\
\hline ED_MA & W & W & W & W \\
\hline ED_PVT & W & W & L & W \\
\hline EH_EMN & W & W & W & L \\
\hline EH_QUANT & L & W & W & W \\
\hline EH_ENERG & W & W & W & W \\
\hline EH_TECH & L & L & L & W \\
\hline EH_SBIAS & W & L & W & W \\
\hline EM_ASIA_JP & W & W & L & W \\
\hline EM_GLOBAL & W & W & W & L \\
\hline EM_LAT_AM & L & L & L & W \\
\hline EM_EAST_EU & L & W & L & L \\
\hline FoF_CONSV & W & W & W & W \\
\hline FoF_DIVERS & W & L & & \\
\hline FoF_MKT_DFENS & & &
\end{tabular}


Table 11 cont.

\begin{tabular}{|l|c|c|c|c|}
\hline FWC_CHF & L & L & W & W \\
\hline FWC_EUR & L & L & W & L \\
\hline FWC_GBP & W & W & W & L \\
\hline FWC_JPY & W & W & W & W \\
\hline MCRO_SYST_DIV & W & W & W & W \\
\hline RV_FIAB & W & L & W & W \\
\hline RV_FICA & W & W & L & W \\
\hline RV_FICORP & L & L & W & W \\
\hline RV_MSTRAT & W & W & L & W \\
\hline RV_YEILDAT & L & W & & \\
\hline
\end{tabular}


NOTES 